\title{
Manufacturing Enterprise Network Structure Influencing Mechanism on its Ecological Performance under Different Strategies
}

\author{
Wang Xue-yuan ${ }^{1}$, Liu Cheng-long ${ }^{1}$ and Zhang Yu-feng ${ }^{2}$ \\ 1 School of Management, Harbin University of Science and Technology, \\ P.R.China, 150080 \\ 2 Business School, University of Birmingham, Birmingham United Kingdom, \\ B15 2TY \\ wangxueyuan@hrbust.edu.cn
}

\begin{abstract}
Manufacturing enterprise is the core to enhance country or regional competitive advantage; meanwhile it's the main source of environment pollution. According to configuration theory, only optimal structure can guarantee the realization of strategic target. Therefore, manufacturing enterprise network structure dimension (centrality, transparency, disparity, and complementarity) is confirmed in this paper, and its influencing mechanism on its ecological performance is discovered based on data collection from typical manufacturing enterprise network by regression analysis method. From the research result we can see that efficiency and innovation oriented manufacturing enterprise network ecological performance has different relation with network structure. Efficiency-oriented network should improve its centrality, transparency and complementarity to increase its ecological performance; while for innovation-oriented network, it should keep medium transparency and comparatively higher level disparity to realize ecological development, and the complementarity also should be improved to get higher ecological performance in long run.
\end{abstract}

Keywords: manufacturing enterprise, network structure, influencing mechanism, ecological performance

\section{Introduction}

Manufacturing enterprises absorb lots of employee and make great contribution for country or region development, which receive great attention from government, industrialist and academics; while they also emit polluted air, waste, etc., which destroy our ecological environment. In China, ecological development has become an important strategic choice after many years economic development with high priority, and in the Third Plenary Session of the 18th Central Committee of the Communist Party of China, establish ecological culture has ready become one of the most important strategy needs to be implemented strictly. Therefore, how to improve manufacturing enterprise ecological performance needs to be researched.

Manufacturing enterprise competition is transferred from single enterprise to supply chain or network with the globalization and integration. In the process of their cooperation, related manufacturing enterprises or upwards/downward enterprises (suppliers/distributors) form a network with complex relationship among each other, within which resources transfer frequently among network participants (Sarita Koendjbiharie, et al. 2010) in multi direction[1], which can help participants to access information, resources and new market, get more learning chance \& cooperation opportunities, and create new knowledge (Kuei et al., 2011)[2], therefore network 
becomes a favorable operation approach for manufacturing enterprise. Accordingly, how network realize ecological development in the process of integration become a key point to research.

A research report based on 1,157 surveys and 30 in-depth interviews with executives reveals that, although enterprise of all sizes in all industry sectors understand the importance of globalization and integration operating, few of them really know how to design and operate their network successfully (Business week research services, 2006; Zhang et al. 2011)[3,4]. Configuration theory can be used to describe a state of organization, and Jagjit Singh Srai and Mike Gregory (2008) put configuration concept into operational domain [5]. If a reasonable configuration of network can be confirmed, different network can be designed or developed into optimal orientation to realize good performance. Current research on network configuration is usually on macro level to confirm from which aspects can describe the network well or what the characteristics of network would be for different network (Zhang, et al., 2011)[4], while more detailed description with quantitative analysis is needed in operational level for manufacturing enterprise networks to offer them effective guidance to realize ecological development.

Accordingly, manufacturing enterprise network and its structure dimension would be analyzed in this paper, and questionnaire to reflect manufacturing enterprise network structure condition and its ecologic performance would be designed and sent out to collect effective data, to discover network structure influencing mechanism on its ecological performance, which can guide manufacturing enterprise network to adjust its structure to realize good ecological performance.

\section{Literature Review}

Manufacturing enterprise network is composed by different participants including enterprise, research institute, and university, etc. along the whole manufacturing chain, whose core activity is manufacturing, and other activities play auxiliary role in the network. The manufacturing enterprise network ("A network is a set of nodes and the set of ties representing some relationship or a lack of relationship between the nodes", Brass et al., 2004) has high adaptability and responsiveness (B. R. Barringer and J. S. Harrison, $2000)^{[6,7]}$, which is a favorable organization form for manufacturing enterprises to cultivate its competitive advantages.

Network structure dimension usually can be divided into the following four aspects: network centrality, transparency, disparities and complementarities.

(1) Centrality can reflect network organizational structure. Within some networks, information communication and sharing among network participants should be arranged by manufacturing enterprise in core position, and network participants seldom have change and opportunity to sharing and communicate with each other. In this kind network, resources are arranged and allocated uniformly by core enterprise to realize the effective and recycle utilization of resources among different participants to realize network ecological development. In contrast, in some networks, information sharing is frequent, and participants can communicate with each other frequently, and new ideas or new clean or green technologies would be created much easier, and then the ecological development can be realized based on clean technology, or new green manufacturing flow or ecological manufacturing system. According to current research, project closeness centrality (Chaim Fershtman \& Neil Gandal, 2011) is highly associated with project efficiency[8], the central decision and standard arrangement means high efficiency in action. However, the downside of a high degree of centrality in networks is needed to assimilate diverse suggestions, solutions and ideas to innovate (Perry Smith and Shalley, 2003)[9]. From the analysis we can see that it's hard to say high or low centrality of manufacturing enterprise network is better for network ecological development. In 
different kinds of networks, the optimal configuration of network centrality seems different, thus the theoretical assumption is put forward as follows:

Hypothesis 1: In efficient network, high centrality positively influences manufacturing enterprise network ecological performance.

Hypothesis 2: In innovation network, low centrality positively influences manufacturing enterprise network ecological performance.

(2) Network transparency can reflect network degree of standardization in some extent. If a network has high network transparency, the relationship of participant and their duty and right is clearly understood by themselves, they can finish their task with less resources and lower cost; especially if the requirement of ecological development for different participants are clearly written and announced among network, each participants would strictly implement the regulation and meet ecological index target, therefore the network ecological development is guaranteed. While some network transparency is not so high, only offer guideline for participants, how to do or implement depends on participants themselves. In this case, participants would try their best to find and create new ways to meet ecological index requirement, and new ways may lead to high ecological performance. Network transparency, including actor transparency, dyadic transparency and network structural transparency, will affect network performance (Sarita Koendjbiharie et al., 2010)[1], more definite and clearer the boundary and relation of participants are, more efficient the network is. Bhaskar Chakravorti (2004) state that transparent framework may eliminate different combinations of barriers and enhance motivators [10]; therefore, the participants can make their respective commitments and investments. Although a transparency and clear boundary network system can be useful for controlling resources allocation and will let project become more stable and each project pays more attention on its own task, the boundaries between participants are strong barriers for information and experiences sharing (Dixon, 2000)[11], which will restrain the margins for creative outcomes, so boundaries transparency of network participants should be balanced with interactive control systems (Paolo Canonico, et al., 2010) and the explicit rules[12]. Accordingly, two hypotheses are put forward:

Hypothesis 3: In efficient network, high network transparency positively influences manufacturing enterprise network ecological performance.

Hypothesis 4: In innovation network, downward of high network transparency positively influences network ecological performance.

(3) Network disparities reflect network participants' difference in diverse aspects. If a network has low disparities, all the participants have similar managing concept and culture, especially has the same understanding of ecological development and adopt similar behavior to treat the environments problem, the resources utilization efficiency would be enhanced; while if the participants of work has diverse backgrounds new ecological concept and approaches would be absorbed or created based on systematic integration, thus the network ecological performance may be improved significantly. Disparities includes culture distance (national culture, Hofstede, 1980; organizational culture)[13], geographic distance, and linguistic distance (Henrik Dellestrand \& Philip Kappen, 2012)[14]. National culture differences reside mostly in values, and organization culture differences reside mostly in practice (Hofstede, 1980)[13]. Some argue that in most cases societal and organizational culture dimension scores were closely correlated (Geert Hofstede, 2006)[15]; while some researches find organizational culture difference account for more of the negative effects on joint venture performance, and influences of organizational culture is more dominant. Geographic distance can lead to the increase of transaction cost (Shenkar, 2001)[16], some academics consider within a geographical area network can offer a great number of channels to accelerate fine-grained information which is benefit for innovation (Uzzi, 1997)[17]. Some state that geographic agglomerations are embedded in global production or innovation networks through external linkages (Bathelt et al., 2004)[18], which bring into the critical mass sources of 
new knowledge. While others think localised and distance learning is complementary, it would be optimal to make a balance between local agglomerations and distance cooperation (Belussi \& Sedita, 2012)[19]. Culture and linguistic diversity, which has a dual impact, initially they have a negative impact on performance; Linguistic barriers will cause trouble in communication and the most serious thing is that may create misunderstanding and misconception (Ambos, 2009)[20]. Slone et al. (2011) consider that geographic and time differences, cross-cultural difference, will add complexity for global network management. However, sustained interaction and learning of culturally and linguistically diverse networks may ultimately result in multicultural networks outperforming and higher adaptation (Semra Comu et al., 2011)[21,22]. The proper and favorable disparity degree would be different for diverse manufacturing enterprise network. Usually, high disparity is preferable in innovation network to realize ecological development, while low disparity is preferable in efficient network to improve ecological performance. Therefore the theoretical assumption is put forward as following:

Hypothesis 5: In efficient network, downward of high network disparity positively influences network ecological performance.

Hypothesis 6: In innovation network, high network disparity positively influences manufacturing enterprise network ecological performance.

(4) Network complementary can reflect participants' reciprocal degree, especially the waste or by-product continuous utilization among network. Participants with complementary resources and high reciprocal degree have greater enthusiasm for integration and more benefits to innovation (Annemien J. J. Pullen et al., 2012)[23]. Usually long-term participants know each other well, learning complementary will decrease for they own more common and mutual knowledge, in contrast the new participants may offer more complementary information or knowledge. In some network, there are lots of new participants, which have high complementary, while the cooperation experience among them are lacked. They can use complementary resources to realize zero waste output by their complementary cooperation. While some networks have long cooperation experience, while new ecological knowledge complementary is low, it's hard for them to create new ways to realize ecological development, but for the long and effective cooperation, they can use resources with high efficiency and make good allocation and arrangement among network, therefore they can realize ecological delveopement by effective operation and resources scale effect. The research of Jan Kratzer et al. (2010) shows that network efficiency and the creativity of network relate negatively in some aspects, such as network structure of old-timers and newcomers [24]. "Old-timers are likely to enhance network efficiency but may display limited ability to innovate, newcomers will generate more variance but may find it more difficult to coordinate their efforts due to lack of shared experience". Thus the other two hypothesis are proposed.

Hypothesis 7: In efficient network, downward of network complementarity (more older-timers in network) positively influences manufacturing enterprise network ecological performance.

Hypothesis 8: In innovation network, upward of network complementarity positively influences network ecological performance.

\section{Evaluation of Network Structure, Strategy and Ecological Performance}

(1) Network structure. According to the above analysis, network centrality can be reflected by information sharing and communicating ways and the communicating condition among network participants. If in manufacturing enterprise network, participants information transferring should be arranged by core enterprise, and if there are seldom communication among participants, the network centrality is high, vise versa. 
Network transparency can be reflected by two aspects. One is whether the participants' duty and right are clearly defined, and whether the layer of network is definitive to all participants; the other is whether the files or regulation are written in detailed, and most of operation problems can be solved based on current regulation. Network disparity can be evaluated by participant's differences in culture, geography and linguistics. They are the main source of participant's disparity. If high layer managers or engineers can communicate well and ordinary staff among network can also communicate with each other well, and if participants have similar strategic understanding and also the operational concept or behavior habit/custom, and if network participants are in the some continent and next to each other, we can judge the network has low disparity, vise versa. Network complementary can be reflected by their by-product or waste recycle condition among network and their clear or green knowledge and technique complementary. If upward enterprise by-product or waste could be the materials or resources for downward enterprise, and for the whole network there is zero waste output, and if the participants among network have complementary knowledge or technique which is benefit for new clean technology innovation or business process reengineering, we can say the network has high complementary; in contrast, if the participants offer similar resources to realize large scale effect and high efficient utilization of resources based on long term cooperation experience, we would say network complementary is not so high.

(2) Network efficiency. Effectiveness and efficiency are the two fundamental performance measures for organization. They say effectiveness is defined as a measure of how closely an organization's output meets its goal, and efficiency is defined as a measure of how economically the organisation's resources are utilized when producing the required output (Schmidt and Finnigan, 1992)[25]. Heikkila (2002) state organisations and partners must maintain a competitive advantage and position, and improve performance through efficient operations, and efficiency refers to profitability and reliability[26]. Chris K.Y. Lo et al. (2009) consider efficiency is time-based, which can be reflected by operational efficiency and mixed impacts on financial performance (McGuire and Dilts, 2008)[27,28]. There are lots of detailed metrics to weigh efficiency, such as reduction of cost (total cost, product cost, process cost, Constantin Blome et al., 2013)[29], improvement of quality, inventory turnover and capacities balance (Pamela Danese and Pietro Romano, 2011)[30]. In a whole, efficiency means that network can meet the target well and have high reliability to finish its goals, including cost budget, time schedule and quality requirement; meanwhile it has attractive economic or financial performance, such as higher return of investment or shorter payback period, etc.

(3) Network innovation. Generally innovation has three types: product, process and system (organization or administrative) innovation. Dong-Young Kim et al. (2012) divide innovation into different types, such as product innovation (radical/incremental), process innovation (radical/incremental) and administrative innovation [31]. While some divide innovation into administrative, technological innovation: administrative innovation refers to the application of new ideas to improve organizational structures and systems or processes, technological innovation refers to create novelty products or services with high technology. Some academics research single type innovation, such as process innovation or product innovation, some are explored them together (Martinez Costa and Martinez Lorente, 2008)[32]. Usually innovation could be reflected by three aspects, all of which will be useful to improve network ecological performance.

-Product innovation. New product and service ideas generation, new product or service success rate, R\&D inputs, total innovation expenditures, patent citations, patent counts, and new product announcements (Hagedoorn and Cloodt, 2003) etc. could reflect product innovation performance[33]. Joaqu'n Alegre and Ricardo Chiva (2008) state product innovation implies two conditions: novelty and use, accordingly innovation efficacy and innovation efficiency are used to reflect innovation performance [34]. Innovation efficacy reflects the degree of success of an innovation. On the other hand, innovation efficiency 
reflects the effort made to achieve that degree of success. Manufacturing network is not entity (data collection is difficult) and the purpose of which is not limited with patent (Sara Thorgren et al., 2009)[35], therefore, use of innovation or innovation efficiency is more important. Additionally, new products or services quality should be measured by their novelty (different from competitors) and their creativeness (highly technological advanced compared with their competitors) two aspects.

-Process innovation. John E. Ettlie and Ernesto M. Reza (1992) consider process innovation is to creating effective new patterns from the many alternative ways of accomplishing changes[36]. Markus Baer and Michael Frese (2003) state process innovations can be defined as deliberate and new organizational attempts to change production and service processes, such as business process reengineering (BPR), simultaneous engineering and so on[37]. Process innovation means that manufacturing enterprise network changes original process for production or service by design or selecting a new and different method or way, which contribute to the improvement of network ecological performance.

-System innovation. Shu-hsien Liao et al. (2008) point out besides product or service innovation and a new operation procedure, a new management strategy is also important, and most successful innovations are the result of changes in concepts[38]. Therefore, a new management approach/concept adopted in manufacturing network is the result of system innovation.

(4) Ecological performance. Kim (2000) emphasized the importance of a long-term relationship in network cooperation, based on the belief that such a long-term relationship would eventually benefit all of the participants (Iyer and Bergen, 1997)[39,40]. Manufacturing enterprise network is not only to enhance ecological performance of leading enterprises but also improve the ecological performance of other participants. Margot J. Hutchins and John W. Sutherland (2008) state in order to achieve sustainable development[41], we must have an adequate understanding of how industrial actions affect the environment or how today's decisions may impact future generations (society development). In manufacturing enterprise network decision-making, minimization of emissions (waste) and other environment effects should be taken into consideration.

Thus, ecological network performance could be evaluated by leading and related participants (beneficiaries) improvement in ecological development, and their contribution to environment development.

According to above analysis, we get manufacturing enterprise network structure, strategy and ecological performance evaluating contents which can be seen in table 1 . In order to get the detailed condition of network, a Likert seven-scale method is used to scoring network from the aspects of network structure, strategy and ecological performance.

Table 1. Manufacturing Network Evaluation on Network Structure, Strategy and Ecological Performance

\begin{tabular}{|c|c|c|c|c|c|}
\hline $\begin{array}{c}\text { Question } \\
\text { NO. }\end{array}$ & Circumstance & $\begin{array}{cc}\text { Disagree } & \begin{array}{c}\text { Partly } \\
\text { disagree }\end{array} \\
1 & 2\end{array}$ & $\begin{array}{c}\text { Neutral } \\
3\end{array}$ & $\begin{array}{l}\text { Partly } \\
\text { agree } \\
4\end{array}$ & $\begin{array}{c}\text { Agree } \\
5\end{array}$ \\
\hline \multicolumn{6}{|c|}{ Network structure } \\
\hline 3 & $\begin{array}{l}\text { In network, communication among network } \\
\text { members has always been arranged by the core } \\
\text { organization(s). Network members cannot } \\
\text { communicate freely among themselves. } \\
\text { Network boundary is clearly defined. Network } \\
\text { members fully understand their own specific tasks } \\
\text { and their linkages to the overall strategic } \\
\text { objectives. } \\
\text { Geographic/cultural/linguistic disparity among } \\
\text { network members is not obvious. }\end{array}$ & & & & \\
\hline
\end{tabular}




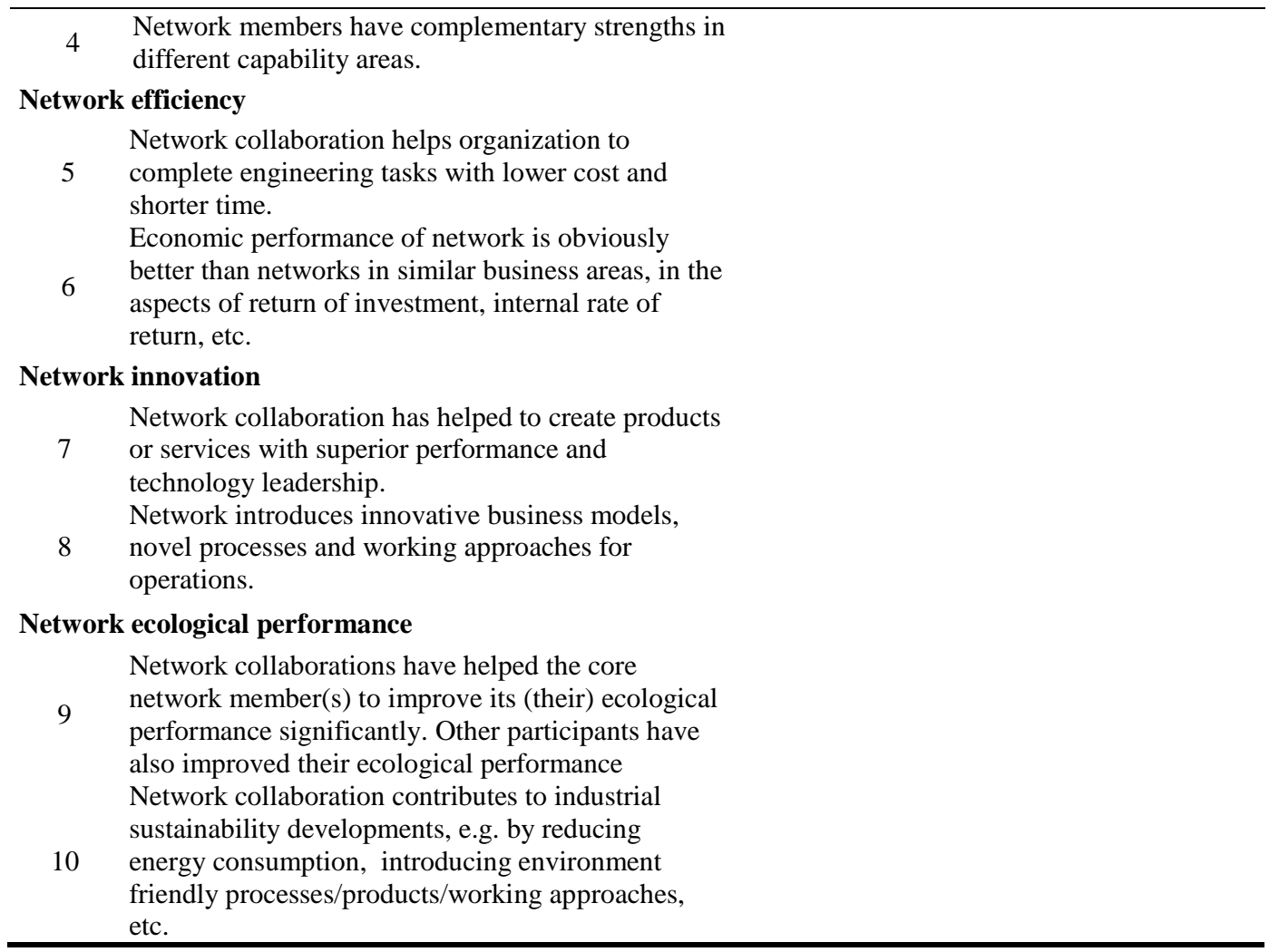

\section{Network Structure, Strategy and Ecological Performance Relationship Confirmation}

In order to get proper data from manufacturing enterprise network, five manufacturing enterprise network is selected, including Harbin Hafei Automobile Industry Group Co Ltd, Harbin Measuring \& Cutting Tool Group Co. Ltd., lenovo, Huawei, Zhongxing Telecommunication Equipment Corporation. Some networks are efficiency orientated and some are innovation oriented. In order to have a comprehensive understanding of network operation, senior engineers or managers who take responsibility of network operation or basically know the operating condition of the whole network are selected to score the items in table 1 . We sent the table to forty participants based on previous cooperation or related social network, and twenty-eight effective marking tables are collected; the effective collecting rate is $70 \%$.

Regression analysis method is used to identify the influencing mechanism of network centrality, transparency, disparity and complementarity on manufacturing enterprise network by SPSS 17.0. For each relationship confirmation, three simulating methods are adopted, which includes linear, quadratic and logistic fitting methods. According to network character and performance on efficiency and innovation, two group networks are divided based on the average score of question $5 \& 6$, and question $7 \& 8$. If the average score of question $5 \& 6$, is equal to or above 2.5 , the network would be belonged to efficiency oriented network, which is the same for innovation oriented network, if for a network its average score of question $5 \& 6$ is equal to the average score of question 7 $\& 8$, which is also equal to or above 2.5 , the network would be belonged to both efficiency-oriented and innovation-oriented network.

After treatment, there are 14 innovation oriented networks, and 17 innovation oriented networks, which means three networks belong to both of the two kind networks. The best fitting formula is selected based on significance level of F-test, which can be seen in table 2. 
Table 2. Regression Analysis Results

\begin{tabular}{|c|c|c|c|c|c|c|c|c|c|c|}
\hline \multirow{2}{*}{$\begin{array}{c}\text { Strategy } \\
\text { orientation }\end{array}$} & \multirow{2}{*}{$\begin{array}{l}\text { The Relation with } \\
\text { ecological } \\
\text { performance }\end{array}$} & \multirow{2}{*}{$\begin{array}{l}\text { Optimal } \\
\text { fitting } \\
\text { formula }\end{array}$} & \multicolumn{5}{|c|}{ Model summary } & \multicolumn{3}{|c|}{ Parameter estimation } \\
\hline & & & $\mathrm{R}^{2}$ & $\mathrm{~F}$ & df1 & df 2 & Sig. & Constant & b1 & b2 \\
\hline \multirow{3}{*}{$\begin{array}{l}\text { Efficiency } \\
\text { orientated }\end{array}$} & centrality & linear & 0.653 & 22.553 & 1 & 12 & 0.000 & 1.030 & 0.599 & 0.142 \\
\hline & transparency & quadratic & 0.730 & 14.864 & 2 & 11 & 0.001 & 3.143 & -2.190 & 0.881 \\
\hline & disparity & \multicolumn{9}{|c|}{$\mathrm{p}>0.05$, the significance is not obvious } \\
\hline \multirow{5}{*}{$\begin{array}{l}\text { Innovation } \\
\text { oriented }\end{array}$} & complementarity & Logistic & 0.466 & 10.451 & 1 & 12 & 0.007 & 0.969 & 0.694 & 0.140 \\
\hline & centrality & \multicolumn{9}{|c|}{$\mathrm{p}>0.05$, the significance is not obvious } \\
\hline & transparency & quadratic & 0.576 & 7.460 & 2 & 11 & 0.009 & -1.326 & 3.345 & -0.575 \\
\hline & disparity & quadratic & 0.550 & 6.723 & 2 & 11 & 0.012 & 1.536 & 1.527 & -0.302 \\
\hline & complementarity & quadratic & 0.558 & 6.939 & 2 & 11 & 0.011 & 3.433 & -1.497 & 0.433 \\
\hline
\end{tabular}

There are six obvious influencing relationships among network ecological performance and its structure dimensions, the relationship map can be seen in figure 1 and 2 .

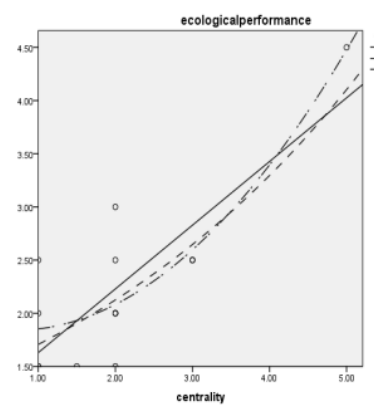

(1-a) centrality

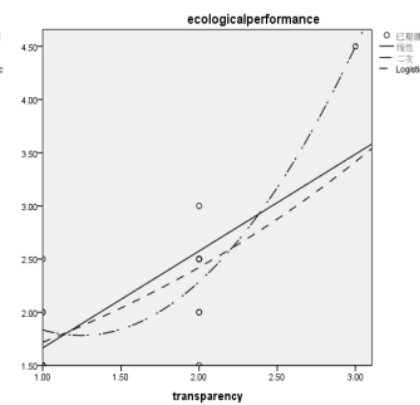

(1-b) transparency

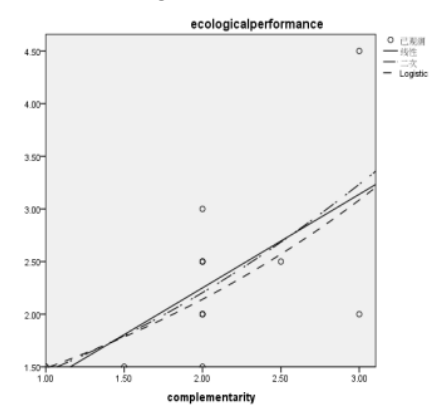

(1-c) complementarity

Figure 1. The Relationship between Ecological Performance of Efficiency-oriented Manufacturing Enterprise Network and Network Structure

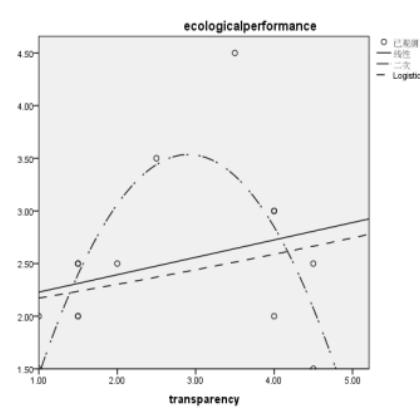

(2-a) transparency

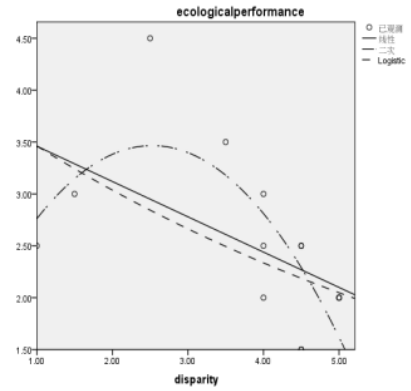

(2-b) disparity

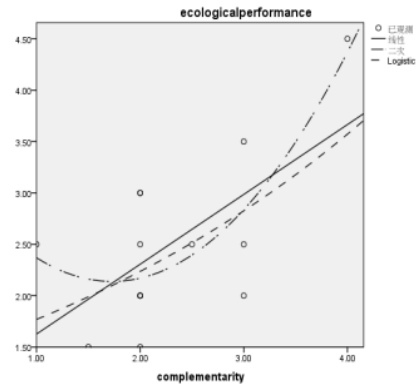

(2-c) complementarity

Figure 2. The Relationship between Ecological Performance of Innovation-oriented Manufacturing Enterprise Network and Network Structure

\section{Results Analysis}

According to regression analysis results, we can see that basically network centrality and transparency is positively related with network ecological performance for efficiencyoriented network. Hypothesis 1 and 3 are proved. Network disparity doesn't have significant influence on ecological development, some networks though have different communicating language, maybe have different culture and in different continent, the network still can make good integration to realize resources recycling and reusing or high utilization of resources based on good operation management and information support. 
For network complementarity, it's positively with both efficiency and innovation oriented network. Knowledge complementarity and upward enterprise by-product or waste transferring to downward enterprise as materials can be benefit for different kinds of networks. While the network has long term cooperating participants usually has more efficient cooperation though the complementarity is low. There is some extent compensation of high efficient cooperation for low complementarity. In innovation network, complementarity research some extent may create new technology or establish new flow obviously. Therefore the complementarity has much more stable relationship with ecological performance for efficiency network than innovation network. Hypothesis 5 and 7 are not proved.

In innovation network, network structure seems have more complex relationship with ecological performance. For network centrality, there is no significant relationship with network ecological performance. In innovation network the centrality is usually low, and participant can communicate with other very well, but the downward or upward of network centrality has no significant influence on ecological performance. Some innovation network though has higher centrality than other networks, which are all in low centrality level, may have better performance on ecological performance. Network transparency increase can help innovation network improve its ecological performance by regularize its flow and mechanism when the whole network transparency in low level; while when everything has proper framework to abide, the increase of network transparency seem have negative impact on ecological performance for the decreasing of cooperation and coordination among participants. Network disparity has similar relationship with network ecological performance, when network has high disparity the downward of disparity would negatively influence network ecological performance, for the resource reusing or recycling is hard. While when the disparity for network is proper the downward of disparity will cause the decrease the ecological performance. In innovation network, participants needs disparity, so the turning point happens earlier when the disparity decreases than the turning point happens when network transparency changes. The complementarity of network in a whole has positive relationship with ecological performance in innovation network, while there is a short and little decrease at the beginning of complementarity increase, for the making use of different complementarity needs time and accumulation, if the network in a state of high uniform, it has low capability to integrate and make good use of different resources with high complementarity; however, after a short while the complementarity advantage will appear with the accumulation of cooperating experience. Hypothesis 2, 4, 6 and 8 are not proved in this paper, there are more complex relationships among them.

According to the analysis results, we can see that the favorable manufacturing enterprise network structure for ecological development of efficiency-oriented and innovation-orientated network is different. In order to realize ecological development, efficiency-oriented network should improve its centrality, transparency and complementarity; while for innovation-oriented network, it should keep medium transparency and comparatively higher level disparity to realize ecological development, and the complementarity also should be improved to get higher ecological performance in long run.

\section{Conclusions}

Manufacturing enterprise ecological and network development become a strategic choice currently in China, while what's the optimal structure for network to realize ecological development is not clear. In order to fill this gap, network structure dimension is confirmed first in this paper, and based on network current condition and performance on efficiency and innovation; two type of manufacturing enterprise network is divided. According to the literature analysis, eight theoretical assumptions are proposed. Based on 
marking table and data collection, as well as calculation based on regression analysis method, network structure relationship with ecological performance is discovered for efficiency network and innovation network. And the implication for management is put forward in this paper: Efficiency-oriented network should improve its centrality, transparency and complementarity to increase its ecological development. Innovationoriented network should keep medium transparency and comparatively higher level disparity and high level complementarity to realize ecological development. In this paper, there are some restrictions: First, manufacturing enterprises have diverse field, including oiling, mining, automobile, and aerospace, etc., different manufacturing industry may has its own character, the optimal network structure for them would be different. While in this paper we take manufacturing enterprise as a whole including different industrial field, if possible in the future manufacturing network in different would be selected to make comparison research on their optimal network structure. Second, the samples are limited; if possible more related network and more marking table should be obtained and used for regression analysis to improve the validation of research. In related filed some research could be done further including different industrial filed comparison analysis, we can also offer the structure adjusting tactics for network, ecological developing path and managing method under different manufacturing enterprise network strategy and structure.

\section{Acknowledgements}

$\checkmark$ This work has been supported in part by the research project the Seventh Framework Programme of the European Union through Marie Curie Actions IRSES Europe-China High Value Engineering Network (EC-HVEN), Grant No. PIRSES-GA-2011-295130; The National Natural Science Foundation of China Youth Fund Project (71403070); nature science foundation of Heilongjiang Youth Project province(QC2012C044); Heilongjiang Province philosophy social sciences innovation team construction plan (TD201203)

\section{References}

[1] S. Koendjbiharie, O. Koppius, P. Vervest and E. van Heck, "Network transparency and the performance of dynamic business networks", Digital Ecosystems and Technologies, vol. 4, (2010), pp. 197-202.

[2] C. Kuei, C. N. Madu and C. Lin, "Developing global supply chain quality management systems", International Journal of Production Research, vol. 49, no. 15, (2011), pp. 4457-4481.

[3] "Global engineering development (GPD) - moving from strategy to Execution", BusinessWeek Research Services Reports, BusinessWeek Research Services, (2006).

[4] Y. Zhang and M. Gregory, "Managing global network operations along the engineering value chain", International Journal of Operations \& Production Management, vol. 31, no. 7, (2011), pp. 736-764.

[5] J. S. Srai and M. Gregory, "A supply network configuration perspective on international supply chain development”, International Journal of Operations \& Production Management, vol. 28, no. 5-6, (2008), pp. 386-411.

[6] D. J. Brass, J. Galaskiewicz, R. G. Henrich and W. Tsai, "Taking Stock of Networks and Organizations: A Multilevel Perspective", The Academy of Management Journal, vol. 47, no. 6, (2004), pp. 795-817.

[7] B. R. Barringer and J. S. Harrison, "Walking a Tightrope: Creating Value through Inter-organizational Relationships", Journal of Management, vol. 26, no. 3, (2000), pp. 367-403.

[8] C. Fershtman and N. Gandal, "Direct and indirect knowledge spillovers: the "social network" of opensource projects", Rand Journal of Economics, vol. 42, no. 1, (2011), pp. 70-91.

[9] J. E. P. Smith and C. E. Shalley, "The social side of creativity: A static and dynamic social network perspective", Academy Of Management Review, vol. 28, no. 1, (2003), pp. 89-106.

[10] B. Chakravorti, "The role of adoption networks in the success of innovations: a strategic perspective", Technology in Society, vol. 26, no. 2, (2004), pp. 469-482.

[11] D. M. Gann and A. J. Salter, "Innovation in project-based, service-enhanced firms: the construction of complex products and systems", Research Policy, vol. 29, no. 7, (2002), pp. 955-972.

[12] P. Canonico and J. Söderlund, "Getting control of multi-project organizations: Combining contingent control mechanisms", International Journal of Project Management, vol. 28, no. 8, (2010), pp. 796-806.

[13] G. Hofstede, "Motivation, leadership, and organization: Do American theories apply abroad?", Organizational Dynamics, vol. 9, no. 1, (1980), pp. 42-63. 
[14] H. Dellestrand and P. Kappen, "The effects of spatial and contextual factors on headquarters resource allocation to MNE subsidiaries", Journal Of International Business Studies, vol. 43, no. 3, (2012), pp. 219-243.

[15] G. Hofstede, "What did GLOBE really measure? Researchers' minds versus respondents' minds", Journal of International Business Studies, vol. 37, no. 6, (2006), pp. 882-896.

[16] O. Shenkar, "Cultural distance revisited: Towards a more rigorous conceptualization and measurement of cultural differences", Journal of International Business Studies, vol. 32, (2001), pp. 519-535.

[17] B. Uzzi, "Social structure and competition in inter firm networks: The paradox of embeddedness", Administrative Science Quarterly, vol. 42, no. 1, (1997), pp. 35-67.

[18] H. Bathelt, A. Malmberg and P. Maskell, "Clusters and knowledge: local buzz, global pipelines and the process of knowledge creation", Progress in Human Geography, vol. 28, no. 1, (2004), pp. 31-56.

[19] F. Belussi and S. R. Sedita, "Industrial Districts as Open Learning Systems: Combining Emergent and Deliberate Knowledge Structures", Regional Studies, vol. 46, no. 2, (2012), pp. 165-184.

[20] T. C. Ambos and B. Ambos, "The impact of distance on knowledge transfer effectiveness in multinational corporations", Journal of International Management, vol. 15, no. 1, (2009), pp. 1-14.

[21] R. Slone, S. Becker, H. R. Penton, X. Pu and R. C. McNamee, "Managing Global R\&D Networks", Research-Technology Management, vol. 54, no. 6, (2011), pp. 59-61.

[22] S. Comu, H. I. Unsal and J. E. Taylor, "Dual Impact of Cultural and Linguistic Diversity on Project Network Performance”, Journal Of Management In Engineering, vol. 27, no. 3, (2011), pp. 179-187.

[23] A. J. J. Pullen, P. C. de Weerd, A. J. Groen and O. A. M. Fisscher, "Open Innovation in Practice: Goal complementarity and closed NPD networks to explain differences in innovation performance for SMEs in the Medical Devices Sector”, Journal Of Product Innovation Management, vol. 29, no. 6, (2012), pp. 917-934.

[24] J. Kratzer, R. T. A. J. Leenders and J. M. L. Van Engelen, "The social network among engineering design teams and their creativity: A case study among teams in two product development programs", International Journal of Project Management, vol. 28, no. 5, (2010), pp. 428-436.

[25] W. H. Schmidt and J. P. Finnigan, "The race without a finish line: America's quest for total quality", Business Horizons, vol. 36, no. 5, (1993), pp. 89-90.

[26] H. Jussi, "From supply to demand chain management: efficiency and customer satisfaction", Journal of Operations Management, vol. 20, no. 6, (2002), pp. 747-767.

[27] K.Y. Lo Chris, C. L. Yeung Andy and T. C. E Cheng, "ISO 9000 and supply chain efficiency: Empirical evidence on inventory and account receivable days", International Journal of Production Economics, vol. 118, no. 2, (2009), pp. 367-374.

[28] S. J. McGuire and D. M. Dilts, "The financial impact of standard stringency: An event study of successive generations of the ISO 9000 standard", International Journal of Production Economics, vol. 113, no. 1, (2008), pp. 3-22.

[29] D. A. Wuttke, C. Blome and M. Henke, "Focusing the financial flow of supply chains: An empirical investigation of financial supply chain management", International Journal of Production Economics, vol. 145, no. 2, (2013), pp. 773-789.

[30] P. Danese and P. Romano, "Supply chain integration and efficiency performance: a study on the interactions between customer and supplier integration", Supply Chain Management-an International Journal, vol. 16, no. 4, (2011), pp. 220-230.

[31] D. Kim, V. Kumar and U. Kumar, "Relationship between quality management practices and innovation", Journal of Operations Management, vol. 30, no. 4, (2012), pp. 295-315.

[32] M. Martinez and A. R. Martinez, "Does quality management foster or hinder innovation? An empirical study of Spanish companies", Total Quality Management \& Business Excellence, vol. 19, no. 3, (2008), pp. 209-221.

[33] J. Hagedoorn and M. Cloodt, "Measuring innovative performance: is there an advantage in using multiple indicators?”, Research Policy, vol. 32, no. 8, (2003), pp. 1365-1379.

[34] J. Alegre and R. Chiva, "Assessing the impact of organizational learning capability on product innovation performance: An empirical test", Tech-innovation, vol. 28, no. 6, (2008), pp. 315-326.

[35] S. Thorgren, J. Wincent and D. Örtqvist, "Designing inter-organizational networks for innovation: An empirical examination of network configuration, formation and governance", Journal of Engineering and Technology Management, vol. 26, no. 3, (2009), pp. 148-166.

[36] J. E. Ettlie and E. M. Reza, "Organizational Integration and Process Innovation", The Academy of Management Journal, vol. 5, no. 4, (1992), pp. 795-827.

[37] M. Baer and M. Frese, "Innovation is not enough: climates for initiative and psychological safety, process innovations, and firm performance", Journal of Organizational Behavior, vol. 24, no. 1, (2003), pp. $45-68$

[38] S. Liao, W. Fei and C. Liu, "Relationships between knowledge inertia, organizational learning and organization innovation", Technovation, vol. 28, no. 4, (2008), pp. 183-195.

[39] J. G. Kim, K. B. Lee, S. B. Lee, D. B. Lee and S. J. Kim, "The effect of long-term application of different organic material sources on chemical properties of upland soil", Korean Journal of Soil Science and Fertilizer, vol. 33, (2000), pp. 416-431. 
International Journal of $u-$ and $\mathrm{e}-$ Service, Science and Technology

Vol.9, No. 1 (2016)

[40] A. V. Iyer and M. E. Bergen, "Quick response in manufacturer-retailer channels", Management Science, vol. 43, no. 4, (1997), pp. 559-570.

[41] M. J. Hutchins and J. W. Sutherland, "An exploration of measures of social sustainability and their application to supply chain decisions", Journal of Cleaner Production, vol. 16, no. 15, (2008), pp. 16881698. 